\title{
Four-Layered Membrane in the Plastids of Galls of Cuscuta australis
}

It is well known that plastids are delimited by a double membrane, enclosing a light space ${ }^{1}$.

Such a type of membrane was also observed in plastids of Cuscuta australis stems ${ }^{2}$. On the contrary, the plastid observed in the galls produced on Cuscuta stems following egg deposition by Smicronyx, a galligen Curculionida, are delimited by 2 double membranes, as shown in Figure 1.

The gall can be divided into 3 zones, where plastids can vary from a type with a very reduced lamellar system to a type having the typical ultrastructure of actively synthetizing organules ${ }^{3}$.

However, all the plastids, whatever their degree of development, show the above-mentioned 2 double membranes. These 4 delimiting membranes are arranged in such a way as to form 2 double membranes, i.e. they are coupled 2 by 2 . The distance between the inner and the outer membranes of the 2 pairs of membranes is almost the same as that observed between 2 normal delimiting membranes; on the contrary, the distance between 2 membranes of each pair is very reduced, as shown in Figure 2.

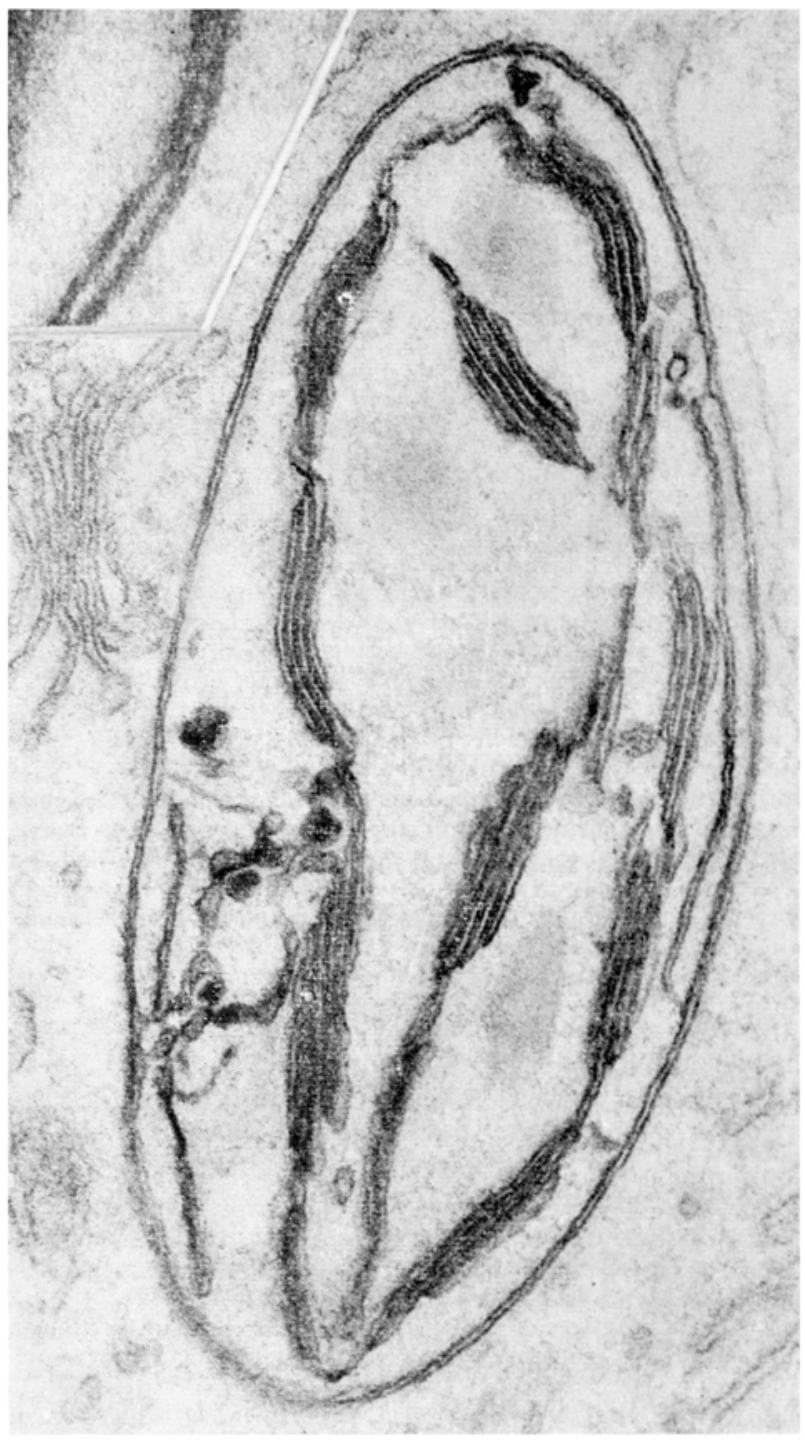

Fig. 1. Chloroplasts, of the inner zone of the gall, of C. australis, delimited by a four-layered membrane. $\times 38,000$. Inset $\times 105,000$.

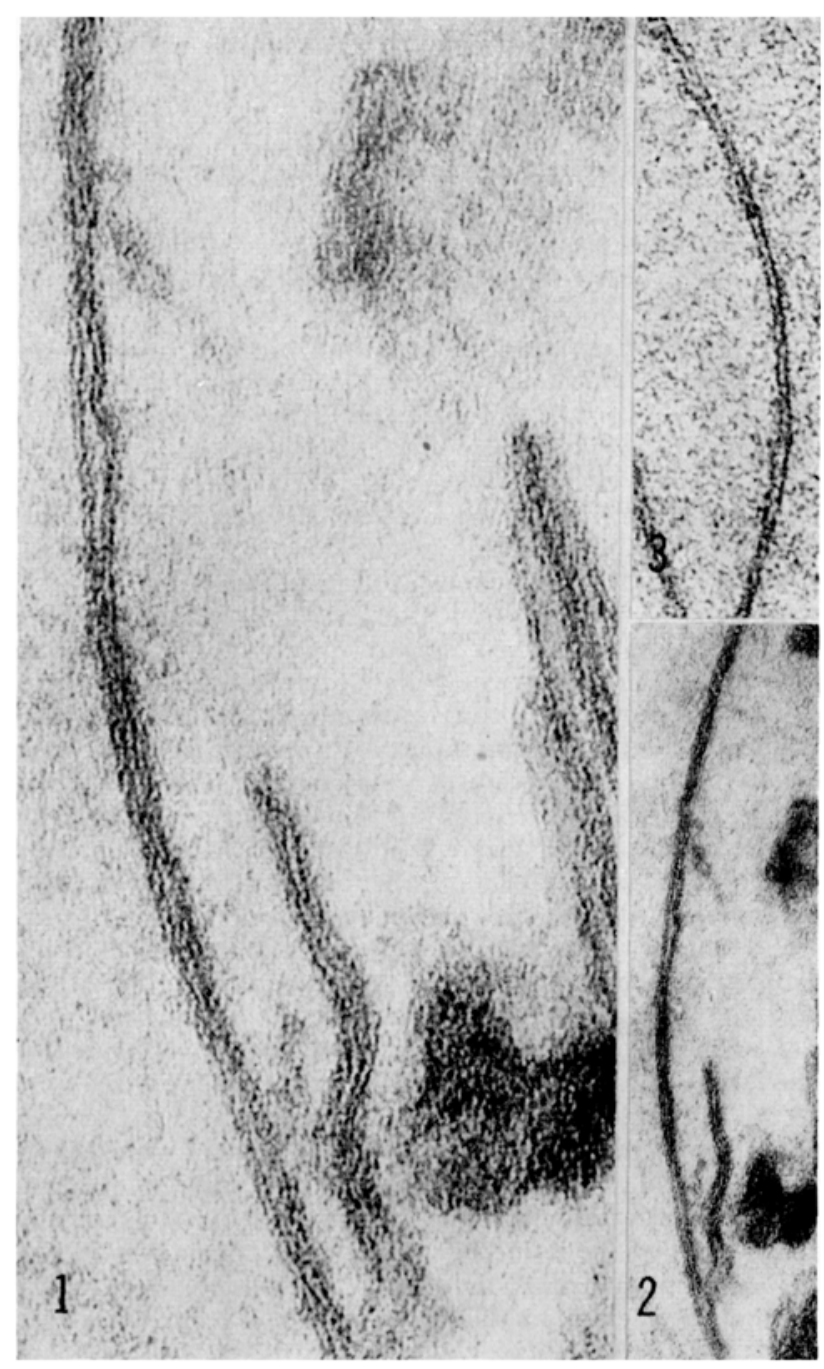

Fig. 2. (1) Particular of gall chloroplast showing the four-layered membrane. $\times 158,000$. (2) Same particular of gall chloroplast of C. australis with the four-layered membrane. $\times 54,000$. (3) Particular of normal stem plastid of $C$. australis showing a double membrane. $\times 54,000$.

Riassunto. Nelle cellule delle galle dei fusti di Cuscuta australis (causate da un curculionide) sono presenti plastidi che, indipendentemente dal loro grado di sviluppo, sono delimitati da 4 membrane, appaiate 2 a 2 . La distanza fra la membrana più esterna e quella più interna è molto simile a quella che si osserva fra le normali doppie membrane dei plastidi, mentre le membrane di ogni coppia sono molto più ravvicinate.

G. L.AUDI

Istituto di Botanica, Facoltà di Agraria, Università Cattolica del Sacro Cuore, Piacenza (Italy), 15 February 1968.

1 A. Frey-WySSling and K. MUnlethaler, Ultrastructural Plant Cytology (Elsevier Publications, Amsterdam 196.5).

- G. Laudr, Caryologia 17, 139 (1964).

- G. Laudr, G. Bot. ital, in press (1968). 